\title{
Review of the assessment and management of neonatal abstinence syndrome
}

\author{
Sarah Mary Bagley ${ }^{1 *}$, Elisha M Wachman², Erica Holland ${ }^{3}$ and Susan B Brogly ${ }^{4}$
}

\begin{abstract}
Neonatal abstinence syndrome (NAS) secondary to in-utero opioid exposure is an increasing problem. Variability in assessment and treatment of NAS has been attributed to the lack of high-quality evidence to guide management of exposed neonates. This systematic review examines available evidence for NAS assessment tools, nonpharmacologic interventions, and pharmacologic management of opioid-exposed infants. There is limited data on the inter-observer reliability of NAS assessment tools due to lack of a standardized approach. In addition, most scales were developed prior to the prevalent use of prescribed prenatal concomitant medications, which can complicate NAS assessment. Nonpharmacologic interventions, particularly breastfeeding, may decrease NAS severity. Opioid medications such as morphine or methadone are recommended as first-line therapy, with phenobarbital or clonidine as second-line adjunctive therapy. Further research is needed to determine best practices for assessment, nonpharmacologic intervention, and pharmacologic management of infants with NAS in order to improve outcomes.
\end{abstract}

Keywords: Neonatal abstinence syndrome assessment, Neonatal abstinence syndrome management, Neonatal abstinence syndrome treatment

\section{Introduction}

Between 2000 and 2009, antepartum opioid use increased from 1.19 to 5.63 per 1000 live births in the United States. Concurrently, the incidence of neonatal abstinence syndrome (NAS) increased from 1.20 to 3.39 per 1000 live births, and related hospitalization costs increased from $\$ 39,400$ to $\$ 53,400$ per infant with NAS [1]. NAS is characterized by gastrointestinal, respiratory, autonomic, and central nervous system disturbances from opioid withdrawal that affect critical regulatory areas of postnatal life adaptation [2]. Fifty to eighty percent of opioid-exposed infants require pharmacologic treatment for NAS [3-5]. Recently, studies have suggested that in-utero exposure to nicotine, selective serotonin reuptake inhibitors, and benzodiazepines may influence NAS [6,7]. A better understanding of the effects of maternal opioid-agonist medications, breastfeeding, genetic factors, and polypharmacy on the severity of withdrawal and

\footnotetext{
* Correspondence: Sarah.Bagley@bmc.org

${ }^{1}$ Section of General Internal Medicine, Boston University School of Medicine, 801 Mass Ave. 2nd Floor, Boston, MA 02118, USA

Full list of author information is available at the end of the article
}

the need for pharmacotherapy will help to optimize assessment and management $[3,6,8,9]$.

Despite this growing problem, great variability persists in the assessment and management of opioid-exposed infants, with only half of neonatal intensive care units (NICUs) with accredited fellowships having a protocol for NAS management [10]. In addition, no medications are currently approved by the FDA for use in NAS management or prenatal opioid dependence. Buprenorphine and methadone are currently labeled as FDA Category C: "Animal reproduction studies have shown an adverse effect on the fetus and there are no adequate and wellcontrolled studies in humans, but potential benefits may warrant use of the drug in pregnant women despite potential risks." It is important to recognize that although these drugs may not be FDA approved for use in pregnancy, the risks associated with continued use of illicit drugs or misuse of prescription medications is far greater. In addition to the benefits of methadone or buprenorphine to treat withdrawal symptoms and reduce cravings, pregnant women in treatment may have access to other treatment such as counseling, infection screening, and fetal growth monitoring, which can lead 
to improved pregnancy and neonatal outcomes [11]. There are decades of experience with methadone use in pregnancy, and it has long been considered the gold standard in treating pregnant women with opioid dependence. Methadone has been shown to decrease intrauterine growth restriction, prematurity, and fetal distress compared to heroin use only [11-14]. Recently, the World Health Organization included a recommendation for women with opioid dependence to be maintained on either methadone or buprenorphine during pregnancy [15]. While some studies suggest that prenatal buprenorphine decreases NAS severity compared to methadone, the interpretation of these comparative studies is limited by important differences in women treated with buprenorphine versus methadone, such as bias from study dropout and confounding by indication [3,16-21]. Nonetheless, it is important that women have access to two effective treatment options and that both have reasonable safety profiles for the exposed fetus.

Given this variability in clinical practice, several clinical narrative reviews have been written to guide practice for NAS management, focusing primarily on pharmacologic treatment regimens $[4,5,22,23]$. Those reviews have commented on the lack of randomized trials or solid evidence guiding current assessment and management of NAS. The objective of this review is to summarize available evidence on the assessment and management of infants exposed to opioids in utero, including assessment tools used for NAS scoring, nonpharmacologic interventions, and pharmacologic management of NAS.

\section{Methods}

We conducted a systematic search of the published English-language literature of studies on 1) assessment of NAS, 2) nonpharmacologic interventions for NAS, and 3) pharmacologic treatment of NAS. To identify articles, two of the authors (SMB and EH) searched PubMed and the Cochrane Database and searched the references in identified articles. Articles published between 1975 and November 15, 2013, are included in the results.

For assessment articles, the search terms included were: neonatal abstinence syndrome assessment, neonatal abstinence score, neonatal drug withdrawal score, neonatal drug withdrawal assessment, Finnegan score, Lipsitz score, and modified Finnegan score. For the nonpharmacologic intervention articles, we used the search terms: neonatal $a b$ stinence syndrome nonpharmacologic treatment, neonatal abstinence syndrome management, and neonatal abstinence syndrome treatment. For pharmacologic management, the search terms were: neonatal abstinence syndrome pharmacologic treatment, neonatal abstinence syndrome management, and neonatal abstinence syndrome treatment.

Different inclusion criteria were applied for the three study categories due to varying availability of data and types of studies conducted in each area. We included studies of assessment tools developed for the clinical diagnosis and management of NAS. For nonpharmacologic treatment, we included studies composed of cohort, case series, case-control, and randomized controlled trials (RCTs). For pharmacologic treatment, only RCTs and nonrandomized experimental studies were included. For nonpharmacologic intervention and pharmacologic treatment studies, articles were only included if they defined objective NAS outcome measures. We excluded studies that examined the use of paregoric as pharmacologic treatment because although it was commonly used in NAS treatment in the past, it is no longer recommended due to issues with impurity $[4,24]$. NAS outcomes measures extracted included inter-rater variability for NAS scoring, length of pharmacologic treatment for NAS, peak NAS scores, mean NAS scores, and length of hospital stay.

\section{Results}

\section{Assessment}

Of 368 articles identified through our search terms, eight specifically pertained to the evaluation of assessment tools for NAS. Of those eight articles, four are included in this review. In addition, we have included the results of the assessment tool used in the MOTHER (Maternal Opioid Treatment: Human Experimental Research) study. The four excluded studies were eliminated due to clinical issues. For example, one excluded study used infant sucking as the study outcome of NAS improvement; however, routine use of this measurement tool is not practical for most nurseries because it requires an instrument to measure sucking, which is not practical, and whose use is uncommon [25]. A second excluded study evaluated neurobehavioral assessment using the NICU Network Neurobehavioral Scale, which was not meant to be used in routine clinical care for the treatment of withdrawal in infants with NAS [26]. A third excluded study used an adjuvant tool whose use is not intended to replace a full assessment tool [27]. The fourth excluded study examined the use of an actigraph (portable motion detector that measures movement), which would not be practical for clinical use [28].

The assessment tools for NAS are provided in Table 1. They were all developed in the United States. The first was the Neonatal Abstinence Syndrome Score (NASS), or what is commonly referred to as the Finnegan Score (FS). This scale or a modified version is the most widely used NAS scale in the US $[3,5]$. It had a high inter-rater reliability coefficient of 0.82 when initially developed $[29,30]$. The second tool developed was the Narcotic Withdrawal Score, or the Lipsitz Score [31]. There was no inter-rater reliability determined; only infants who scored above a certain threshold had been exposed to 
Table 1 Studies of tools to assess neonatal abstinence syndrome

\begin{tabular}{|c|c|c|c|}
\hline Reference & Index vs. reference group(s) & Scale & Primary results \\
\hline \multirow[t]{4}{*}{ Finnegan, 1975 [29] } & $\begin{array}{l}37 \text { infants assessed with NASS vs. } \\
37 \text { infants born prior to development } \\
\text { of NASS }\end{array}$ & $\begin{array}{l}\text { Neonatal Narcotic } \\
\text { Abstinence Scoring System }\end{array}$ & $\begin{array}{l}\text { Mean inter-rater reliability } \\
\text { coefficient: } 0.82(0.75-0.96)\end{array}$ \\
\hline & Exposure methadone and heroin & $\begin{array}{l}20 \text { items, weighted on } \\
\text { pathologic severity }\end{array}$ & $\begin{array}{l}\text { Management of NAS without } \\
\text { drug Rx: } 30 \% \text { vs. } 46 \%\end{array}$ \\
\hline & & & LOS: 6 days vs. 8 days \\
\hline & & & Total Rx days decreased by $25 \%$ \\
\hline \multirow[t]{2}{*}{ Lipsitz, 1975 [31] } & $\begin{array}{l}41 \text { infants evaluated by } 2 \text { pediatric } \\
\text { residents, placed in } 5 \text { groups, one } \\
\text { group which was opioid exposed }\end{array}$ & Narcotic Withdrawal Score & $\begin{array}{l}\text { Only the infants exposed to opioids } \\
\text { had scores } \geq 5 \text {; concluded that a score } \\
>4 \text { suggests a clinical threshold for Rx }\end{array}$ \\
\hline & Exposure methadone and heroin & 11 items, scored 0-3 based on severity & \\
\hline \multirow[t]{3}{*}{ Green, 1981 [32] } & $\begin{array}{l}\text { Infants exposed to methadone } \\
\text { or heroin }(n=50)\end{array}$ & Neonatal Narcotic Withdrawal Index & Inter-rater reliability coefficient: $0.771^{*}$ \\
\hline & Control infants $(n=40)$ & 7 items, scored $0-2$ based on severity & $\begin{array}{l}\text { Mean NAS score on day } 2 \\
\text { of life: } 1.57 \text { vs. } 3.08^{*}\end{array}$ \\
\hline & & $\begin{array}{l}\text { 7th item is "other" and includes } \\
12 \text { other symptoms }\end{array}$ & \\
\hline \multirow[t]{3}{*}{ Zahorodny, 1998 [33] } & $\begin{array}{l}\text { Group A: opioid-exposed infants } \\
\text { with NAS }(n=30)\end{array}$ & Neonatal Withdrawal Inventory & $\begin{array}{l}\text { Group A: inter-rater reliability } \\
\text { coefficient: } 0.89-0.98\end{array}$ \\
\hline & $\begin{array}{l}\text { Group B: opioid infants with NAS }(n=12) \\
\text { and nonopioid-exposed controls }(n=13)\end{array}$ & 8 items given predetermined weights & $\begin{array}{l}\text { Group B: sensitivity and specificity } \\
\text { for NAS diagnosis: } 100 \%, 100 \%\end{array}$ \\
\hline & $\begin{array}{l}\text { Group C: opioid-exposed infants } \\
\text { with NAS }(n=25)\end{array}$ & & $\begin{array}{l}\text { Group C: sensitivity and specificity for } \\
\text { Rx threshold vs. the NASS: } 100 \%, 100 \%\end{array}$ \\
\hline \multirow[t]{2}{*}{ Jones, 2010 [3] } & $\begin{array}{l}131 \text { opioid-exposed infants, } \\
\text { scored using the same scale }\end{array}$ & MOTHER NAS scale (modified Finnegan) & Intraclass correlation coefficient $>0.94$ \\
\hline & Exposure methadone or buprenorphine & & \\
\hline
\end{tabular}

Abbreviations: NAS Neonatal Abstinence Syndrome, NASS Neonatal Abstinence Scoring System, Rx Treatment, LOS Length of Hospital Stay.

*indicated $\mathrm{p}<0.05$

opioids in utero, and that score was established as the threshold score for NAS treatment. The next scale developed is called the Neonatal Narcotic Withdrawal Index, which has an inter-rater reliability coefficient of $r=0.771$ $(\mathrm{p}<0.01)$ [32]. The fourth scale we reviewed is the Neonatal Withdrawal Inventory (NWI). The NWI was able to correctly identify withdrawing infants with a specificity and sensitivity of 100 percent when Finnegan's NASS was used as the gold standard. The inter-rater reliability coefficient was $0.89-0.98$ for the NWI, compared with $0.7-0.88$ for Finnegan's NASS [33]. The final scale is the MOTHER NAS scale, which is a modified Finnegan scale. They estimated an intraclass correlation coefficient for the degree of agreement between an expert rater and a site rater (the MOTHER trial was an international, multisite trial) and found that the lowest coefficient exceeded 0.94 [3].

\section{Nonpharmacologic interventions}

Of the 879 articles we identified pertaining to nonpharmacologic interventions, 13 were included in this review.

\section{Infant feeding method}

The majority of evidence for the nonpharmacological management of NAS is in the area of infant feeding method.
Breastfeeding is recommended in stable mothers on methadone and buprenorphine maintenance therapy who are not concurrently using illicit drugs. The definition of stable will vary by institution; for example, the policy may state that in order to be eligible to breastfeed, the mother will have had no positive urine toxicology screens and been adherent with treatment in the last trimester $[11,22,34,35]$. Transfer of methadone and buprenorphine into breast milk is minimal and unrelated to maternal dose $[8,36]$. Breastfeeding has been shown to act as an analgesic for infants and is established as beneficial for soothing agitated infants [37].

Seven studies were identified that examined the role of infant feeding method on NAS outcomes [9,38-43]. All studies were retrospective cohorts of primarily full-term infants exposed to methadone, heroin, and buprenorphine and were determined to have NAS symptoms. Studies did not consistently differentiate between expressed breast milk and breastfeeding. Some studies did not compare exclusive breastfeeding versus combination feeding and those fed with formula only. Duration of breastfeeding was also not defined by the majority of studies. Five of the seven studies specified the NAS scoring assessment used, but there was variation both in the threshold for initiating 
pharmacologic treatment and the type of pharmacologic treatment used. Criteria for permitting breastfeeding were not described in every study, which introduced bias that was not addressed in these studies.

The primary findings of the seven studies are presented in Table 2, indicating an overall decreased need for pharmacologic treatment, a decrease in NAS scores, and decreased length of pharmacologic therapy and hospitalization for infants who were breastfed primarily or breastfed to any extent. In four of the studies, length of hospitalization was 3-19 days shorter in breastfed infants $[9,38,41,43]$. In four of the studies, infants who were breastfed to any extent had up to 30 percent reduction in their need for pharmacologic treatment for NAS $[9,38,41,42]$. In addition, one study found that predominantly breastfed infants demonstrated signs of withdrawal significantly later than formula-fed infants ( 10 vs. 3 days; $\mathrm{p}<0.001$ ), with decreased Finnegan withdrawal scores in the first 9 days of life [38].

\section{Other nonpharmacologic interventions}

Other nonpharmacologic interventions that have been described include rooming-in, bed type, positioning of the infant, and non-insertive acupuncture (NIA). The primary findings are presented in Table 2. Two retrospective studies of rooming-in found overall decreased length of hospital stay and duration of therapy $[44,45]$. Two studies examined the role of bed type on NAS outcomes. In the first study, infants randomly assigned to a rocking bed with accompanying intrauterine sounds had higher mean withdrawal scores that were statistically nonsignificant and an increase in sleep disturbance that was only statistically nonsignificant on day 7 of life [46]. In the second study, in which infants were randomly assigned to an experimental nonoscillating waterbed or a regular crib, those in the waterbed required less pharmacologic treatment for NAS [47]. In another study on positioning, 48 infants were randomly assigned to either supine or prone sleeping positions; those infants placed in a supine position had significantly higher peak and mean withdrawal scores and higher mean caloric intake [48]. Finally, one study examined the role of NIA on NAS as adjunctive therapy for infants receiving treatment for NAS. Infants included in the study were diagnosed although their pharmacologic treatment was not specified. After the NIA sessions, babies were subjectively noted to have improved sleep, with decreased restlessness and improved feeding [49].

\section{Pharmacologic management}

Out of 940 published articles identified using our search terms for pharmacologic treatment, seven studies met our inclusion criteria. Of note, there are studies included in the Cochrane Reviews that are not included in our review because they examined studies using paregoric or unpublished data. The primary results of the seven selected studies are presented in Table 3.

Two studies compared morphine with phenobarbitone and with diluted tincture of opium (DTO), respectively. In the first study, 75 infants were enrolled in a doubleblind RCT to compare morphine with phenobarbitone in infants with two consecutive Lipsitz scores of $>4$. Median treatment duration was significantly shorter in the morphine group. Infants treated with phenobarbitone required more frequent second-line treatment with chloral hydrate $(47 \%$ vs. $35 \% ; \mathrm{p}=0.11)$ and admission to a specialty care baby unit $(62 \%$ vs. $30 \%$; $p=0.04)$ [50]. The second study compared randomized treatment of NAS with tincture of opium versus morphine in 33 infants and used the FS assessment for NAS treatment initiation and discontinuation. Both length of treatment and length of stay were longer in the morphine group (29.8 vs. 26.9 days and 37.5 vs. 32.4 days; $\mathrm{p}>0.05$ ) [51].

Two studies examined the use of buprenorphine to treat NAS. In both studies, a modified FS was used to assess infants, and three consecutive scores of $\geq 24$ was the threshold for treatment. The first study enrolled 26 infants to a Phase I, randomized, open label, activecontrol study. The active-control arm therapy was neonatal opium solution. Although designed as a safety study, the mean length of treatment for the buprenorphine group (22 vs. 32 days) and of hospital stay (27 vs. 38 days) was clinically but not statistically significant [52]. In the second study of a revised dosing schedule based on these safety data, statistically significant differences were seen in length of treatment and length of stay (Table 3) [53].

Three studies examined the efficacy of an adjunct medication versus first-line therapy alone to reduce treatment duration and hospital stay for infants with NAS, all of which were RCTs (Table 3). Adjunct medication with clonidine (two studies) and phenobarbital (one study) was started at the same time as the first-line opioid in all three studies. These studies showed that adjunct therapy could reduce the duration of treatment with first-line therapy at clinically important levels, resulting in an average cost savings of $\sim \$ 36,000$, but that the duration of phenobarbital treatment after discharge could be long, with a range of 2-9 months. Finally, when clonidine was compared to phenobarbital as an adjunct medication, infants treated with phenobarbital had a shorter duration of treatment [54-56].

\section{Discussion}

The initial development of NAS scoring systems in the 1970s was a crucial turning point in the care of infants exposed to opioids when pediatricians recognized the need for a consistent way to assess exposure. However, 
Table 2 Studies of the nonpharmacologic management of neonatal management syndrome

\begin{tabular}{|c|c|c|c|c|c|}
\hline Reference & Study design & Study objective & Index vs. reference group(s) & Assessment tool & Results \\
\hline \multirow[t]{2}{*}{$\begin{array}{l}\text { Abdel-Latif, } \\
2006[38]\end{array}$} & Retrospective Cohort & $\begin{array}{l}\text { To determine association } \\
\text { between breastfeeding } \\
\text { and NAS outcomes }\end{array}$ & $\begin{array}{l}\text { Breastfed infants } \\
\text { with NAS }(n=85)\end{array}$ & Finnegan Score & $\begin{array}{l}\text { Rx for NAS: OR }=0.36 \\
(C l 0.18-0.71)^{*}\end{array}$ \\
\hline & & & $\begin{array}{l}\text { Formula-fed infants } \\
\text { with NAS }(n=105)\end{array}$ & & $\begin{array}{l}\text { Mean LOS: } 14.7 \text { (SD 14.9) } \\
\text { vs. } 19.1 \text { (SD 15.0) days** }\end{array}$ \\
\hline \multirow[t]{2}{*}{$\begin{array}{l}\text { Dryden, } \\
2009[42]\end{array}$} & Retrospective Cohort & $\begin{array}{l}\text { To determine association } \\
\text { between breastfeeding } \\
\text { and NAS outcomes }\end{array}$ & $\begin{array}{l}\text { Breastfed infants } \\
\text { with NAS }(n=99)\end{array}$ & Modified Lipsitz & $\begin{array}{l}\text { Rx for NAS: OR }= \\
0.55(\mathrm{Cl} 0.34-0.88)^{*}\end{array}$ \\
\hline & & & $\begin{array}{l}\text { Formula-fed infants } \\
\text { with NAS }(n=351)\end{array}$ & & \\
\hline \multirow[t]{3}{*}{$\begin{array}{l}\text { McQueen, } \\
2011 \text { [39] }\end{array}$} & Retrospective Cohort & $\begin{array}{l}\text { To determine association } \\
\text { between breastfeeding } \\
\text { and NAS outcomes }\end{array}$ & $\begin{array}{l}\text { Breastfed infants } \\
\text { with NAS }(n=8)\end{array}$ & Modified Finnegan & $\begin{array}{l}\text { Mean \# of NAS scores: } \\
25.0 \text { (SD 23.5) vs. } 56.2 \\
\text { (SD 39.1) vs. } 95.6 \text { (SD 34.6)* }\end{array}$ \\
\hline & & & $\begin{array}{l}\text { Combination-fed infants } \\
\text { with NAS }(n=11)\end{array}$ & & $\begin{array}{l}\text { Mean NAS score } 4.9 \text { (SD 2.9) } \\
\text { vs. } 6.5 \text { (SD 3.7) vs. } 6.9 \text { (SD 4.2)* }\end{array}$ \\
\hline & & & $\begin{array}{l}\text { Formula-fed infants } \\
\text { with NAS }(n=9)\end{array}$ & & \\
\hline \multirow[t]{3}{*}{$\begin{array}{l}\text { Pritham, } \\
2012[43]\end{array}$} & Retrospective Cohort & $\begin{array}{l}\text { To determine association } \\
\text { between breastfeeding } \\
\text { and NAS outcomes }\end{array}$ & $\begin{array}{l}\text { Breastfed with } \\
\text { NAS }(n=14)\end{array}$ & Not specified & Mean LOS: -3.3 (SE 1.7) days \\
\hline & & & $\begin{array}{l}\text { Infants combination-fed } \\
\text { with NAS }(n=22)\end{array}$ & & \\
\hline & & & $\begin{array}{l}\text { Formula-fed infants } \\
\text { with NAS }(n=96)\end{array}$ & & \\
\hline \multirow[t]{2}{*}{$\begin{array}{l}\text { O'Connor, } \\
2013[40]\end{array}$} & Case Series & $\begin{array}{l}\text { To describe association } \\
\text { between breastfeeding } \\
\text { and NAS outcomes }\end{array}$ & $\begin{array}{l}\text { Breastfed infants } \\
\text { with NAS }(n=65)\end{array}$ & Modified Finnegan & $\begin{array}{l}\text { Mean NAS score: } 8.83 \\
\text { (SD 3.56) vs. } 9.65 \text { (SD 2.58) }\end{array}$ \\
\hline & & & $\begin{array}{l}\text { Formula-fed infants } \\
\text { with NAS }(n=20)\end{array}$ & & Rx for NAS: $23.1 \%$ vs. $30.0 \%$ \\
\hline \multirow[t]{2}{*}{$\begin{array}{l}\text { Wachman, } \\
2013 \text { [9] }\end{array}$} & Prospective Cohort & $\begin{array}{l}\text { To determine association } \\
\text { of genetic variables } \\
\text { with NAS outcomes }\end{array}$ & $\begin{array}{l}\text { Breastfed infants } \\
\text { with NAS }(n=38)\end{array}$ & Modified Finnegan & Rx for NAS: $50 \%$ vs. $77 \% *$ \\
\hline & & & $\begin{array}{l}\text { Formula-fed infants } \\
\text { with NAS }(n=48)\end{array}$ & & $\begin{array}{l}\text { Mean LOS: } 15.8(\mathrm{Cl} 11.5-20.1) \\
\text { vs. } 27.4(\mathrm{Cl} 22.5-32.3) \text { days* }\end{array}$ \\
\hline \multirow[t]{2}{*}{$\begin{array}{l}\text { Welle-Strand, } \\
2013 \text { [41] }\end{array}$} & Ambi-directional Cohort & $\begin{array}{l}\text { To determine association } \\
\text { between breastfeeding } \\
\text { and NAS }\end{array}$ & $\begin{array}{l}\text { Breastfed infants } \\
\text { with NAS }(n=95)\end{array}$ & Modified Finnegan & Rx for NAS: $53 \%$ vs. $80 \%{ }^{*}$ \\
\hline & & outcomes & $\begin{array}{l}\text { Formula-fed infants } \\
\text { with NAS }(n=29)\end{array}$ & & $\begin{array}{l}\text { Mean length of Rx: } \\
28.6 \text { (SD 19.1) vs. } \\
46.7 \text { (SD 26.3) days* }\end{array}$ \\
\hline \multirow[t]{4}{*}{$\begin{array}{l}\text { Hunseler, } \\
2013[44]\end{array}$} & Retrospective Cohort & $\begin{array}{l}\text { To describe association } \\
\text { between rooming-in } \\
\text { and NAS outcomes }\end{array}$ & $\begin{array}{l}\text { NAS infants exposed to } \\
\text { rooming-in }(n=24)\end{array}$ & Finnegan & $\begin{array}{l}\text { Finnegan Score > 12: } \\
6.3 \% \text { vs. } 6.4 \%\end{array}$ \\
\hline & & & $\begin{array}{l}\text { Control NAS } \\
\text { infants }(n=53)\end{array}$ & & Rx for NAS: $79.2 \%$ vs. $88.7 \%$ \\
\hline & & & & & $\begin{array}{l}\text { Mean length of } \mathrm{Rx} \text { : } \\
27 \text { vs. } 32.5 \text { days }\end{array}$ \\
\hline & & & & & Mean LOS: 38 vs. 41.5 days \\
\hline \multirow[t]{3}{*}{$\begin{array}{l}\text { Abrahams, } \\
2007 \text { [45] }\end{array}$} & Retrospective Cohort & $\begin{array}{l}\text { To describe association } \\
\text { between rooming-in } \\
\text { and NAS outcomes }\end{array}$ & $\begin{array}{l}\text { Infants with } \\
\text { NAS exposed to } \\
\text { rooming-in }(n=32)\end{array}$ & Modified Finnegan & $\begin{array}{l}\text { Mean length of Rx: } 5.9 \text { vs. } \\
18.6 \text { days*; } 5.9 \text { vs. } 18.6 \text { days* }\end{array}$ \\
\hline & & & $\begin{array}{l}\text { Control infants } \\
\text { with NAS }(n=38) \\
\text { (historical comparison) }\end{array}$ & & $\begin{array}{l}\text { Mean LOS: } 11.8 \text { vs. } 23.5 \\
\text { days; } 11.8 \text { vs. } 25.9 \text { days* }\end{array}$ \\
\hline & & & $\begin{array}{l}\text { Control infants } \\
\text { with NAS }(n=36) \\
\text { (from another institution) }\end{array}$ & & \\
\hline
\end{tabular}




\section{Table 2 Studies of the nonpharmacologic management of neonatal management syndrome (Continued)}

\begin{tabular}{|c|c|c|c|c|c|}
\hline \multirow[t]{2}{*}{$\begin{array}{l}\text { D'Apolito, } \\
1999[46]\end{array}$} & $\begin{array}{l}\text { Nonblinded Random } \\
\text { Assignment of } \mathrm{Rx}\end{array}$ & $\begin{array}{l}\text { To determine the association } \\
\text { between infants sleeping } \\
\text { in a rocking bed vs. controls } \\
\text { with NAS outcomes }\end{array}$ & $\begin{array}{l}\text { Infants with NAS exposed } \\
\text { to rocking bed }(n=7)\end{array}$ & Finnegan & $\begin{array}{l}\text { Mean NAS score on day } \\
7 \text { of intervention: } 10.2 \\
\text { (SD 2.1) vs. } 8.0 \text { (SD 1.8) }\end{array}$ \\
\hline & & & $\begin{array}{l}\text { Control infants } \\
\text { with NAS }(n=7)\end{array}$ & & \\
\hline \multirow[t]{2}{*}{$\begin{array}{l}\text { Oro, } \\
1988[47]\end{array}$} & $\begin{array}{l}\text { Randomized Assignment } \\
\text { of Rx with Matched } \\
\text { Controls }\end{array}$ & $\begin{array}{l}\text { To determine the association } \\
\text { between infants sleeping } \\
\text { in a waterbed vs. controls } \\
\text { and NAS outcomes }\end{array}$ & $\begin{array}{l}\text { Infants with NAS exposed } \\
\text { to a waterbed }(n=15)\end{array}$ & Finnegan & $\begin{array}{l}\text { Maximum NAS score: } \\
6.2 \text { (SD 0.7) vs. } 6.4 \text { (SD 1.0) }\end{array}$ \\
\hline & & & $\begin{array}{l}\text { Control infants } \\
\text { with NAS }(n=15)\end{array}$ & & $\begin{array}{l}\text { Mean LOS: } 10.5 \text { (SD 1.2) } \\
\text { vs. } 11.5 \text { (SD 3.4) days }\end{array}$ \\
\hline \multirow[t]{2}{*}{$\begin{array}{l}\text { Maichuk, } \\
1999[48]\end{array}$} & $\begin{array}{l}\text { Randomized to } \\
\text { Intervention; Nurses } \\
\text { Blinded to Hypothesis }\end{array}$ & $\begin{array}{l}\text { To determine the association } \\
\text { between sleeping position } \\
\text { with NAS outcomes }\end{array}$ & $\begin{array}{l}\text { Infants with NAS placed in } \\
\text { prone position }(n=25)\end{array}$ & Finnegan & $\begin{array}{l}\text { Maximum NAS score: } \\
10.52(\text { SD 2.08) vs. } 13.17 \\
(\text { SD 2.03)* }\end{array}$ \\
\hline & & & $\begin{array}{l}\text { Infants with NAS } \\
\text { placed in the supine } \\
\text { position }(n=23)\end{array}$ & & $\begin{array}{l}\text { Mean NAS score: } 5.11 \\
\text { (SD 0.64) vs. } 7.60 \text { (SD 0.70)* }\end{array}$ \\
\hline $\begin{array}{l}\text { Filippelli, } \\
2012 \text { [49] }\end{array}$ & Case Series & $\begin{array}{l}\text { To describe the possible effects } \\
\text { of NIA on infants with NAS }\end{array}$ & $\begin{array}{l}\text { Infants with NAS } \\
\text { exposed to NIA }(n=54)\end{array}$ & Not applicable & $\begin{array}{l}\text { Chart review revealed } \\
\text { improvements in calming, } \\
\text { sleep, and feeding }\end{array}$ \\
\hline
\end{tabular}

Abbreviations: NAS Neonatal Abstinence Syndrome, Rx Treatment, \# Number, LOS Length of Hospital Stay, OR Odds ratio, CI 95\% confidence interval, SD Standard deviation, SE Standard error.

${ }^{*} \mathrm{p}<0.05$.

since that time, the most commonly used FS has been modified and is used differently across institutions. Nurseries and NICUs have highly variable practices that range from use of published abstinence tools to inconsistent assessment strategies $[4,10,57]$. As the incidence and clinical impact of NAS rises, it is critical for infant care that clinicians employ a common, objective, and validated tool to guide diagnosis and treatment of NAS. In other disease states and syndromes, there are agreedupon criteria for diagnosis, and the same standards should be expected for infants with NAS. Without consistency, it is impossible to assure quality care. The American Academy of Pediatrics (AAP) recommends use of a standardized tool such as the gold-standard Finnegan abstinence assessment for evaluation of NAS [4]. They also recommend an inter-observer reliability program offered for quality improvement efforts. We recommend the use of such established educational programs utilizing the FS manual and DVD (such as that offered by Neo Advances) to standardize scoring among care providers [58]. This standardization may lead to a decrease in the extent of pharmacotherapy used and length of hospitalization needed for affected infants across the United States. The Lipsitz tool includes similar signs and symptoms, but is shorter. Despite the widespread use of these various tools, validation and inter-observer reliability data is lacking. Infants are typically scored using various tools every 3-4 hours starting shortly after birth and are monitored for 5-10 days for signs of opioid withdrawal in the hospital. If infants meet a threshold score on the assessment tool, such as $>8$ on the commonly used FS, they are typically started on pharmacologic therapy.
Morphine and methadone remain the two most commonly used first-line medications, with lack of evidence for which agent is superior. Morphine is given orally and is typically dosed every $3-4$ hours at $0.3-1.0 \mathrm{mg} / \mathrm{kg} /$ day, titrated to effect, and then weaned every 24-48 hours. Methadone is also given orally and dosed every $4-12$ hours, titrated in a similar range of $0.3-1.0 \mathrm{mg} / \mathrm{kg} /$ day, and then weaned over time. Methadone-weaning protocols vary greatly, with some institutions weaning this medication as an outpatient treatment over a longer period of time. Administration of second-line agents for more severe withdrawal consists of a variety of agents including phenobarbital, clonidine, and clonazepam [4,5,24].

Although limited, the available evidence suggests that nonpharmacologic interventions may provide some benefit for infants with NAS by decreasing clinical symptoms and the need for pharmacologic therapy. Standard practice for treating drug-exposed infants includes limiting exposure to sounds and lights and promoting clustering of care, swaddling, and holding, as well as breastfeeding for eligible patients. Evidence is growing that breastfeeding is beneficial for this population [9,38-43]. Breastfeeding is recommended by AAP for the first 6 months of life for all infants without contraindications. Although specific criteria vary by institution, the general recommendation is that infants exposed to opioids in utero should be breastfed if the mother is enrolled in a substance abuse program. Even in those mothers who are eligible, there have generally been low breastfeeding rates in this population, likely secondary to inherent feeding difficulties in these infants $[12,34,35,59]$. Other interventions such as rooming-in may also be beneficial and cost 
Table 3 Studies of pharmacologic treatment for neonatal abstinence syndrome

\begin{tabular}{|c|c|c|c|c|c|c|}
\hline Reference & Design & Purpose & $\begin{array}{l}\text { Comparison } \\
\text { (Index vs. Reference) }\end{array}$ & $\begin{array}{l}\text { Assessment } \\
\text { measure }\end{array}$ & Primary outcome & Results \\
\hline Jackson, 2004 [50] & Double-blind RCT & $\begin{array}{l}\text { Efficacy of opioid vs. phenobarbitone } \\
\text { as first-line therapy }\end{array}$ & $\begin{array}{l}\text { Morphine }(n=41) \\
\text { Phenobarbitone }(n=34)\end{array}$ & Lipsitz & Mean length of $\mathrm{Rx}$ & 8 vs. 12 days* (unadjusted) \\
\hline \multirow[t]{2}{*}{ Langenfeld, 2005 [51] } & $\begin{array}{l}\text { Randomized Trial, } \\
\text { Blinding Not Specified }\end{array}$ & $\begin{array}{l}\text { Compare tincture of opium } \\
\text { to oral morphine }\end{array}$ & Morphine $(n=17)$ & Finnegan & Mean length of $\mathrm{Rx}$ & 29.8 vs. 26.9 days \\
\hline & & & $\begin{array}{l}\text { Tincture of Opium } \\
(n=16)\end{array}$ & & Mean LOS & 37.5 vs. 32.4 days \\
\hline \multirow[t]{2}{*}{ Kraft, 2008 [52] } & $\begin{array}{l}\text { Phase I, Randomized, } \\
\text { Open Label, Active Control }\end{array}$ & $\begin{array}{l}\text { Feasibility and safety of } \\
\text { buprenorphine in Rx of NAS }\end{array}$ & Buprenorphine $(n=13)$ & Modified Finnegan & Mean length of $\mathrm{Rx}$ & 22 (SD 12) vs. 32 (SD 16) days \\
\hline & & & $\begin{array}{l}\text { Neonatal opium } \\
\text { solution }(n=13)\end{array}$ & & Mean LOS & 27 (SD 11) vs. 38 (SD 13) days \\
\hline \multirow[t]{2}{*}{ Kraft, 2011 [53] } & $\begin{array}{l}\text { Phase I, Randomized, } \\
\text { Open Label, Active Control }\end{array}$ & Feasibility and safety of buprenorphine & Buprenorphine $(n=12)$ & Modified Finnegan & Mean length of $\mathrm{Rx}$ & 23 vs. 38 days* \\
\hline & & & Morphine $(n=12)$ & & Mean LOS & 23 vs. 42 days \\
\hline \multirow[t]{3}{*}{ Coyle, 2002 [54] } & $\begin{array}{l}\text { Partially Randomized, } \\
\text { Controlled Trial }\end{array}$ & $\begin{array}{l}\text { Assess whether Rx with } \\
\text { DTO + phenobarbital vs. DTO } \\
\text { alone is better }\end{array}$ & $\begin{array}{l}\text { DTO + phenobarbital } \\
(n=10)\end{array}$ & Finnegan & Finnegan Scores & $\begin{array}{l}\text { Infants in placebo group, } \\
\text { spent more time with FS }>7^{*}\end{array}$ \\
\hline & & & DTO + placebo $(n=10)$ & & & $\begin{array}{l}\text { Infants in phenobarbital group } \\
\text { spent more time with } \mathrm{FS}<5^{*}\end{array}$ \\
\hline & & & & & Mean LOS & Mean: 38 vs. 79 days* \\
\hline \multirow[t]{2}{*}{ Agthe, 2009 [55] } & $\begin{array}{l}\text { Randomized, Double- } \\
\text { Blinded Controlled Trial }\end{array}$ & $\begin{array}{l}\text { To assess use of clonidine as an } \\
\text { adjunct therapy to opioids to } \\
\text { manage NAS }\end{array}$ & Clonidine $(n=40)$ & Modified Finnegan & Mean length of $\mathrm{Rx}$ & $\begin{array}{l}11(95 \% \mathrm{Cl} 8-15) \text { vs. } \\
15(95 \% \mathrm{Cl} 12-17) \text { days }\end{array}$ \\
\hline & & & Placebo $(n=40)$ & & & \\
\hline \multirow[t]{2}{*}{ Surran, $2013[56]$} & $\begin{array}{l}\text { Randomized, Nonblinded } \\
\text { Controlled Trial }\end{array}$ & $\begin{array}{l}\text { Clonidine versus phenobarbital } \\
\text { to reduce \# days of Rx with } \\
\text { morphine sulfate }\end{array}$ & Phenobarbital $(n=34)$ & Modified Finnegan & $\begin{array}{l}\text { Length of Rx with } \\
\text { morphine sulfate }\end{array}$ & $\mathrm{B}=-4.6$ days $(95 \% \mathrm{Cl} 0.3-8.9)^{*}$ \\
\hline & & & Clonidine $(n=32)$ & & & \\
\hline
\end{tabular}

Abbreviations: NAS Neonatal Abstinence Syndrome, Rx Treatment, \# Number, LOS Length of Hospital Stay, DTO Diluted Tincture of Opium.

*indicated $\mathrm{p}<0.05$. 
effective. Both breastfeeding and rooming-in can provide opportunities for bonding and also normalize the postpartum process for women who may feel vulnerable and stigmatized because of their opioid use history. As it would be difficult to conduct randomized trials of interventions that are current standard of care, further studies should focus on how to increase the rates of breastfeeding and rooming-in. The limited available evidence about NIA suggests it may be beneficial, but more studies are needed and a randomized controlled design would be feasible.

There are currently no FDA-approved medications for NAS, and the data supporting one specific treatment is lacking. The studies examining pharmacotherapy efficacy are small; they have used different assessment tool and protocols to escalate and wean medications and were inconsistently adjusted for covariates such as maternal smoking history, exposure to other substances, and feeding methods and are therefore very difficult to compare. There is a need for high-quality RCTs to determine best practices and to establish safety and efficacy. The AAP recommends use of oral morphine solution or methadone when indicated, but notes that the best options for adjunct therapy are not known as well as the best treatment options for infants with polyexposure [4]. Although preliminary, the use of buprenorphine to treat NAS shows promise, but further research should be done that includes feasibility testing because administering it sublingually might present some administrative challenges.

The number of infants exposed to opioids in utero and developing NAS has dramatically risen in the last 10 years; based on current trends, the incidence will increase over the next decade. In addition, as knowledge about predicting NAS severity based on genetics and prenatal treatment of the mother expand, rigorous highquality research should follow. As illustrated by the evidence for nonpharmacologic interventions, it is crucial to consider the infant with NAS as part of an infantmother dyad because treatment of the infant does not occur in isolation from the mother. Creating a more secure, compassionate, and comfortable environment for the dyad will likely optimize outcomes for both mother and infant. Currently, the care for those infants, including assessment and management, varies widely across the country, and existing guidelines are based on minimal data. We recommend that nurseries adopt standard protocols that include use of published assessment tools and accepted NAS treatment such as morphine and methadone, as well as the training of all staff involved in infant care. Further research is urgently needed to assure the best care for infants with NAS, some of which should focus on the variations of NAS expression.

\section{Competing interests}

The authors declare that they have no competing interests.

\section{Authors' contributions}

$\mathrm{SMB}$ and $\mathrm{SBB}$ were responsible for the conception and design. SMB and $\mathrm{EH}$ performed the literature search. SMB, EMW, and EH reviewed the articles. $\mathrm{SMB}, \mathrm{EW}, \mathrm{EH}$, and SBB drafted the manuscript. All authors read and approved the final manuscript.

\section{Acknowledgments}

SMB is supported by R25DA03211 and R25DA013582 from the National Institute on Drug Abuse.

\section{Author details}

'Section of General Internal Medicine, Boston University School of Medicine, 801 Mass Ave. 2nd Floor, Boston, MA 02118, USA. ²Department of Pediatrics, Boston Medical Center, 771 Albany Street, Dowling 4N 4109, Boston, MA 02118, USA. ${ }^{3}$ Department of Obstetrics and Gynecology, Boston Medical Center, 85 East Concord Street, 6th Floor, Boston, MA 02118, USA.

${ }^{4}$ Department of Epidemiology, Boston University School of Public Health, 715 Albany Street, Talbot Building East, Boston, MA 02115, USA.

Received: 21 February 2014 Accepted: 3 September 2014 Published: 9 September 2014

\section{References}

1. Patrick SW, Schumacher RE, Benneyworth BD, Krans EE, McAllister JM, Davis MM: Neonatal abstinence syndrome and associated health care expenditures: United States, 2000-2009. JAMA 2012, 307(18):1934-1940.

2. Hayes MJ, Brown MS: Epidemic of prescription opiate abuse and neonatal abstinence. JAMA 2012, 307:1974-1975.

3. Jones HE, Kaltenbach K, Heil SH, Stine SM, Coyle MG, Arria AM, O'Grady KE, Selby P, Martin PR, Fischer G: Neonatal abstinence syndrome after methadone or buprenorphine exposure. N Engl J Med 2010, 363(24):2320-2331

4. Hudak ML, Tan RC, Committee on Drugs; Committee on Fetus and Newborn; American Academy of Pediatrics: Neonatal drug withdrawal. Pediatrics 2012, 129(2):e540-e560.

5. Jansson LM, Velez M, Harrow C: The opioid-exposed newborn: assessment and pharmacologic management. J Opioid Manag 2009, 5(1):47-55.

6. Wachman EM, Newby PK, Vreeland J, Byun J, Bonganzi A, Bauchner $\mathrm{H}_{\text {, }}$ Philipp BL: The relationship between maternal opioid agonists and psychiatric medications on length of hospitalization for neonatal abstinence syndrome. J Addict Med 2011, 5(4):293-299.

7. Kaltenbach K, Holbrook AM, Coyle MG, Heil SH, Salisbury AL, Stine SM, Martin PR, Jones HE: Predicting treatment for neonatal abstinence syndrome in infants born to women maintained on opioid agonist medication. Addiction 2012, 107(Suppl 1):45-52.

8. Pritham UA: Breastfeeding promotion for management of neonatal abstinence syndrome. J Obstet Gynecol Neonatal Nurs 2013, 42(5):517-526.

9. Wachman EM, Hayes MJ, Brown MS, Paul J, Harvey-Wilkes K, Terrin N, Huggins GS, Aranda JV, Davis JM: Association of OPRM1 and COMT single-nucleotide polymorphisms with hospital length of stay and treatment of neonatal abstinence syndrome. JAMA 2013, 309(17):1821-1827.

10. Crocetti MT, Amin DD, Jansson LM: Variability in the evaluation and management of opiate-exposed newborns in Maryland. Clin Pediatr 2007, 46(7):632-635

11. ACOG Committee on Health Care for Underserved Women; American Society of Addiction Medicine: ACOG Committee Opinion No. 524: Opioid abuse, dependence, and addiction in pregnancy. Obstet Gynecol 2012, 119(5):1070-1076.

12. World Health Organization: Guidelines for Identification and Management of Substance use and Substance use Disorders in Pregnancy; 2014. Available at http://www.who.int/substance_abuse/publications/pregnancy_guidelines/ en/. Last accessed May 13, 2014.

13. Substance Abuse and Mental Health Services Administration: Medication-Assisted Treatment for Opioid Addiction in Opioid Treatment Programs. In Treatment Improvement Protocol (TIP) Series, No. 43; Available at: http://store.samhsa.gov/product/TIP-43-Medication-AssistedTreatment-for-Opioid-Addiction-in-Opioid-Treatment-Programs/SMA12-4214. Last accessed May 13, 2014. 
14. Zelson C, Lee SJ, Casalino M: Neonatal narcotic addiction. Comparative effects of maternal intake of heroin and methadone. New Engl J Med 1973, 289(23):1216-1220

15. Kandall SR, Albin S, Gartner LM, Lee KS, Eidelman A, Lowinson J: The narcotic-dependent mother: fetal and neonatal consequences. Early Hum Dev 1977, 1(2):159-169.

16. Wilson GS, Desmond MM, Wait RB: Follow-up of methadone-treated and untreated narcotic-dependent women and their infants: health, developmental, and social implications. J Pediatr 1981, 98(5):716-722

17. Simmat-Durand L, Lejeune C, Gourarier L, Groupe d' Etudes Grossesse et Addictions (GEGA): Pregnancy under high-dose buprenorphine. Eur J Obstet Gynecol Reprod Biol Feb 2009, 142(2):119-123.

18. Lacroix I, Berrebi A, Garipuy D, Schmitt L, Hammou Y, Chaumerliac C, Lapeyre-Mestre M, Montastruc JL, Damase-Michel C: Buprenorphine versus methadone in pregnant opioid-dependent women: a prospective multicenter study. Eur J Clin Pharmacol Oct 2011, 67(10):1053-1059.

19. Lejeune C, Simmat-Durand L, Gourarier L, Aubisson S, Groupe d'Etudes Grossesse et Addictions (GEGA): Prospective multicenter observational study of 260 infants born to 259 opiate-dependent mothers on methadone or high-dose buprenorphine substitution. Drug Alcohol Depend 2006, 82:250-257.

20. Kakko J, Heilig M, Sarman I: Buprenorphine and methadone treatment of opiate dependence during pregnancy: comparison of fetal growth and neonatal outcomes in two consecutive case series. Drug Alcohol Depend 2008, 96(1-2):69-78.

21. Bakstad B, Sarfi M, Welle-Strand GK, Ravndal E: Opioid maintenance treatment during pregnancy: occurrence and severity of neonatal abstinence syndrome. A national prospective study. Eur Addict Res 2009 15(3):128-134

22. Velez M, Jansson LM: The opioid dependent mother and newborn dyad: non-pharmacologic care. J Addict Med 2008, 2(3):113-120.

23. Jansson LM, Velez ML: Infants of drug-dependent mothers. Pediatr Rev 2011, 32(1):5-12.

24. Bio LL, Siu A, Poon CY: Update on the pharmacologic management of neonatal abstinence syndrome. J Perinatol 2011, 31(11):692-701.

25. Kron RE, Finnegan LP, Kaplan SL, Litt M, Phoenix MD: The assessment of behavioral change in infants undergoing narcotic withdrawal: comparative data from clinical and objective methods. Addict Dis 1975, 2(1-2):257-275

26. Jones HE, Harrow C, O'Grady KE, Crocetti M, Jansson LM, Kaltenbach K: Neonatal abstinence scores in opioid-exposed and nonexposed neonates: a blinded comparison. J Opioid Manag 2010, 6(6):409-413.

27. Lester BM, Tronick EZ, Brazelton TB: The neonatal intensive care unit network neurobehavioral scale procedures. Pediatrics 2004, 113(3 Pt 2):641-667.

28. O'Brien C, Hunt R, Jeffery HE: Measurement of movement is an objective method to assist in assessment of opiate withdrawal in newborns. Arch Dis Child Fetal Neonatal Ed 2004, 89(4):F305-F309.

29. Finnegan LP, Connaughton JF Jr, Kron RE, Emich JP: Neonatal abstinence syndrome: assessment and management. Addict Dis 1975 2(1-2):141-158

30. Finnegan LP, Kron RE, Connaughton JF, Emich JP: Assessment and treatment of abstinence in the infant of the drug-dependent mother. Int J Clin Pharmacol Biopharm 1975, 12(1-2):19-32.

31. Lipsitz PJ: A proposed narcotic withdrawal score for use with newborn infants. A pragmatic evaluation of its efficacy. Clin Pediatr 1975, 14(6):592-594.

32. Green M, Suffet F: The neonatal narcotic withdrawal index: a device for the improvement of care in the abstinence syndrome. Am J Drug Alcohol Abuse 1981, 8(2):203-213.

33. Zahorodny W, Rom C, Whitney W, Giddens S, Samuel M, Maichuk G, Marshall R: The neonatal withdrawal inventory: a simplified score of newborn withdrawal. J Dev Behav Pediatr 1998, 19(2):89-93.

34. Academy of Breastfeeding Medicine Protocol Committee, Jansson LM: ABM clinical protocol \#21: guidelines for breastfeeding and the drug-dependent woman. Breastfeed Med 2009, 4(4):225-228.

35. Section on Breastfeeding, Johnston M, Landers S, Noble L, Szucs K Viehmann L: Breastfeeding and the use of human milk. Pediatrics 2012, 129(3):e827-e841.
36. Jansson LM, Choo RE, Harrow C, Velez M, Schroeder JR, Lowe R, Huestis MA: Concentrations of methadone in breast milk and plasma in the immediate perinatal period. J Hum Lact 2007, 23(2):184-190

37. Gray L, Miller LW, Philipp BL, Blass EM: Breastfeeding is analgesic in healthy newborns. Pediatrics 2002, 109(4):590-593.

38. Abdel-Latif ME, Pinner J, Clews S, Cooke F, Lui K, Oei J: Effects of breast milk on the severity and outcome of neonatal abstinence syndrome among infants of drug-dependent mothers. Pediatrics 2006, 117(6):e1163-e1169.

39. McQueen KA, Murphy-Oikonen J, Gerlach K, Montelpare W: The impact of infant feeding method on neonatal abstinence scores of methadoneexposed infants. Adv Neonatal Care 2011, 11(4):282-290.

40. O'Connor AB, Collett A, Alto WA, O'Brien LM: Breastfeeding rates and the relationship between breastfeeding and neonatal abstinence syndrome in women maintained on buprenorphine during pregnancy. J Midwifery Womens Health 2013, 58(4):383-388.

41. Welle-Strand GK, Skurtveit S, Jansson LM, Bakstad B, Bjarkø L, Ravndal E: Breastfeeding reduces the need for withdrawal treatment in opioid-exposed infants. Acta Paediatr 2013, 102(11):1060-1066.

42. Dryden C, Young D, Hepburn M, Mactier H: Maternal methadone use in pregnancy: factors associated with the development of neonatal abstinence syndrome and implications for healthcare resources. BJOG 2009, 116(5):665-671.

43. Pritham UA, Paul JA, Hayes MJ: Opioid dependency in pregnancy and length of stay for neonatal abstinence syndrome. J Obstet Gynecol Neonatal Nurs 2012, 41(2):180-190.

44. Hunseler C, Brückle M, Roth B, Kribs A: Neonatal opiate withdrawal and rooming-in: a retrospective analysis of a single center experience. Klin Padiatr 2013, 225(5):247-251.

45. Abrahams RR, Kelly SA, Payne S, Thiessen PN, Mackintosh J, Janssen PA Rooming-in compared with standard care for newborns of mothers using methadone or heroin. Can Fam Physician 2007, 53(10):1722-1730.

46. D'Apolito K: Comparison of a rocking bed and standard bed for decreasing withdrawal symptoms in drug-exposed infants. MCN Am J Matern Child Nurs 1999, 24(3):138-144

47. Oro AS, Dixon SD: Waterbed care of narcotic-exposed neonates. A useful adjunct to supportive care. Am J Dis Child 1988, 142(2):186-188

48. Maichuk GT, Zahorodny W, Marshall R: Use of positioning to reduce the severity of neonatal narcotic withdrawal syndrome. J Perinatol 1999, 19(7):510-513

49. Filippelli AC, White LF, Spellman LW, Broderick M, Highfield ES, Sommers E, Gardiner P: Non-insertive acupuncture and neonatal abstinence syndrome: a case series from an inner city safety net hospital. Glob Adv Health Med 2012, 1(4):48-52

50. Jackson L, Ting A, McKay S, Galea P, Skeoch C: A randomised controlled trial of morphine versus phenobarbitone for neonatal abstinence syndrome. Arch Dis Child Fetal Neonatal Ed 2004, 89(4):F300-F304

51. Langenfeld S, Birkenfeld L, Herkenrath P, Müller C, Hellmich M, Theisohn M: Therapy of the neonatal abstinence syndrome with tincture of opium or morphine drops. Drug Alcohol Depend 2005, 77(1):31-36.

52. Kraft WK, Gibson E, Dysart K, Damle VS, Larusso JL, Greenspan JS, Moody DE, Kaltenbach K, Ehrlich ME: Sublingual buprenorphine for treatment of neonatal abstinence syndrome: a randomized trial. Pediatrics 2008 122(3):e601-e607.

53. Kraft WK, Dysart K, Greenspan JS, Gibson E, Kaltenbach K, Ehrlich ME: Revised dose schema of sublingual buprenorphine in the treatment of the neonatal opioid abstinence syndrome. Addiction 2011, 106(3):574-580.

54. Coyle MG, Ferguson A, Lagasse L, Oh W, Lester B: Diluted tincture of opium (DTO) and phenobarbital versus DTO alone for neonatal opiate withdrawal in term infants. J Pediatr 2002, 140(5):561-564.

55. Agthe AG, Kim GR, Mathias KB, Hendrix CW, Chavez-Valdez R, Jansson L, Lewis TR, Yaster M, Gauda EB: Clonidine as an adjunct therapy to opioids for neonatal abstinence syndrome: a randomized, controlled trial. Pediatrics 2009, 123(5):e849-e856.

56. Surran B, Visintainer P, Chamberlain S, Kopcza K, Shah B, Singh R: Efficacy of clonidine versus phenobarbital in reducing neonatal morphine sulfate therapy days for neonatal abstinence syndrome. A prospective randomized clinical trial. J Perinatol 2013, 33(12):954-959. 
57. Sarkar S, Donn SM: Management of neonatal abstinence syndrome in neonatal intensive care units: a national survey. J Perinatol 2006, 26(1):15-17.

58. Enhancing the Care of Drug-Exposed Infants: Inter-observer reliability program. Available at http://www.neoadvances.com. Last accessed May 13 2104

59. Wachman EM, Byun J, Philipp BL: Breastfeeding rates among mothers of infants with neonatal abstinence syndrome. Breastfeed Med 2010, 5(4):159-164.

doi:10.1186/1940-0640-9-19

Cite this article as: Bagley et al.: Review of the assessment and

management of neonatal abstinence syndrome. Addiction Science \& Clinical Practice 2014 9:19.

\section{Submit your next manuscript to BioMed Central and take full advantage of:}

- Convenient online submission

- Thorough peer review

- No space constraints or color figure charges

- Immediate publication on acceptance

- Inclusion in PubMed, CAS, Scopus and Google Scholar

- Research which is freely available for redistribution 